\title{
The impact of unmanned stores' business models on sustainability
}

\author{
Navodya Denuwara ${ }^{1} \cdot$ Juha Maijala ${ }^{2} \cdot$ Marko Hakovirta $^{1}$
}

Received: 17 June 2021 / Accepted: 23 August 2021 / Published online: 23 September 2021

(c) The Author(s), under exclusive licence to Springer Nature Switzerland AG 2021

\begin{abstract}
Digitalization and big data are continuing to revolutionize industries impacting the global economy, environment, and society as a whole. The retail industry is not an exception and is facing a paradigm shift in many aspects of its operations. One of the latest innovations in this industry is the development of unmanned stores concepts and business models. These novel business models are mostly used in the grocery stores segment with an impetus to eliminate the need for check-out lines and to create more efficiencies in the whole process of the shopping experience. Because of the disruptive nature of this business model, it is important to research the effects of its expansion into society. In this article, we are making a critical analysis of the sustainability impact of unmanned stores and assess the strategic direction and growth strategies of major corporations and organizations within the value chain. We used an unambiguous and straightforward questionnaire as the research tool and the results show grocery as the current target for expansion, however, future expectations from business developers lean heavily towards coffee and books. Interestingly, the investment logic for expected benefits from the participants seemed to be biased towards efficiencies and the value chain benefits seemed to mostly come from the use of big data and data analytics. The most important use of the data was associated with the dynamic pricing models. Additionally, our study shows interesting insight for example to the growth segments, the role of sustainability, and barriers of entry.
\end{abstract}

Keywords Unmanned store $\cdot$ Sustainability $\cdot$ E-commerce $\cdot$ Retail $\cdot$ RFID $\cdot$ Internet of things $\cdot$ Business model

Marko Hakovirta

mjhakovi@ncsu.edu

1 Department of Forest Biomaterials, North Carolina State University, 2820 Faucette Drive, Raleigh, NC 27695-8005, USA

2 Stora Enso Oyj, Helsinki, Finland 


\section{Introduction}

The retail industry is considered to be in a period of rapid transformation due to the introduction of digitalization and e-commerce. Established technologies, such as mobile platforms and emerging technologies, such as big data have advanced retail by extending its ability to deliver a customer experience that it would not have been normally able to reach. Lower prices from the rise of globalization and increasing manufacturing capabilities in China and other developing countries have translated into detrimental news for retailers who cannot match these prices offered through non-physical retail means (Meyer 2018). E-commerce has been said to have brought on the 'retail apocalypse' where many physical stores are closing due to the advent of online retail stores where purchasing and selling are solely conducted through online platforms (Helm et al. 2020).

A way to survive this current conjuncture that impacts most retail industries will be to transition into a new type of retail business model that has yet to be decided on (Traub 2017). However, while the media and companies seem to expect to see the end of brick-and-mortar stores, academic research has yet to prove if this will happen (Keen et al. 2001). This is primarily because this would rely on identifying and mapping consumer behavior and preferences to see which type of retail they would prefer-online or in-store; however, mapping consumer behavior takes a considerable amount of time (Childs et al. 2020). Hence, the most direct current solution to this transformation process is that retailers consider and implement a hybrid model that is one of both worlds: physical and online (Hubner et al. 2016).

Online retailers such as Amazon have already begun to transition to brick-andmortar stores after seeing that physical store retailers such as Target have now developed a strong online business in addition to its physical stores (Brush 2019). This approach is allowing leveraging the strongly established brands to the new enhanced business models that create a more collaborative and responsive value proposition to the customers. The emergence and recent techno-economic feasibility of advanced technologies, such as radio-frequency identification (RFID) tags, artificial intelligence, Internet of Things (IoT), augmented and virtual reality (AR\&VR), and near-field communication (NFC) devices, are now supporting traditional retailers to meet the contemporary expectations of their customers in the form of more efficient and enhanced services (The Insight Partners Report 2020). RFID has been around since the 1980s, and NFC was invented in 2002 by NXP, Sony, and Nokia. Depending on the manufacturer, NFC Chips can cost as low as $\$ 0.03$ per chip (Olenik et. al. 2021), and RFID passive tags can cost anywhere between $\$ 0.07$ and $\$ 0.15$ (RFID Journal 2021), making both very affordable solutions. It is both the emergence and crucial affordability of these types of technology that drives the rise of unmanned stores in the recent retail age.

The most innovative retail concepts focus on an omni-channel experience where a physical and online presence is supplied to the customer at the same time, rather than in separate channels. This omni-channel experience involves meeting consumers on the individual channels they shop at and streamlining 
these channels into a connected experience where the consumers can move around the channels at one time and essentially have a harmonious experience that will produce more sales and engagement for the retailer (Tyrvainen and Karjaluoto 2019). Before omni-channel streamlining became conventional, customers used to visit multiple channels of the same shop for purchasing goods and services; prior to that, there was only the single channel of brick-and-mortar stores for shopping purposes. The difference between multichannel and omnichannel is that for multichannel, there exist different shopping channels for the same brand while omnichannel involves the connectivity experience of all the multiple channels of the same brand. The integration and flexibility, along with the connectivity, of omnichannel, is then contrasted with the single-channel experience of physical retail where the customer experience is limited and rigid throughout the process of entering a store to leaving that store. Unmanned stores epitomize the omnichannel experience not only by this combination of physical and online presence, but also in the service provided during visits to these stores. Checkout-free and automatic pricing models in stores are just some of the ways the omnichannel experience affects day-to-day customers. Because these paradigm changes in retail (transforming from single-channel to multi-channel to omnichannel) create various economic consequences locally and globally, overall societal and environmental impacts are generated as well. This paper serves to examine all three impacts through the lens of sustainability.

Currently, there has been a move towards contact-free shopping, accelerated by the impact of COVID-19. Since grocery shopping is a critical need, grocery stores are essential businesses. However, the risk of spreading viruses and bacteria is high due to the physical nature of shopping for food. McKinsey, in 2020, reported that online grocery shopping almost doubled in Italy during April, and post-pandemic, there will be only a muted return to stores due to the familiarity the public gained with digital shopping (Gunday et al. 2020). It was not just grocery stores that went online, but rather other stores also, such as apparel and cosmetics companies (Yu et al. 2020). Digital retail has caused a structural shift in the number of people who will choose to shop in-person or online and one application of this is unmanned stores. One specific digital practice is for the consumers to compare prices online and the environmental impact of the food they buy. The price and sustainability-conscious consumers have been increasing in number for the past decade, and retailers need to pay attention to them. Unmanned stores are potentially an answer to these types of consumers because of not only the safety aspect of self-service checkout and nonexistent employees but also the dynamic pricing system as well as the availability of fresh food that is sourced sustainably through local food supply systems. The rise and need of unmanned stores have created a unique question on what they do for society and how do they affect consumers? To answer this question, we survey companies at the forefront of this industry globally. Not only are sustainability benefits examined to figure out the effects to the environment and the public, but also the investment side to it and how profitable the venture is compared to the traditional grocery store model.

This article encompasses the first published critical analysis on the sustainability impact of specifically the unmanned stores' concepts and business models and 
explores the major corporations and organizations within the value chain to find their current strategic direction and intent towards unmanned stores. To do this, we examine the unmanned store concepts model itself, current and alternative supply chains, the value chain of the food network, the sustainability of the model, and what effect dynamic pricing has on unmanned models. The reason for this is that many steps go before creating a successful unmanned store that provides economic, social, and environmental benefits. Because of this, we will discuss what types of supply chains are more suitable for this model, what changes will be required from the value chain, what sustainability is in this context, and what role dynamic pricing can play in unmanned stores. These four dimensions of exploration will sufficiently guide in the introduction to the unmanned stores model and the data used is found from 10 experts from the unmanned store field who participated in a survey that looked at the current and future outlook of the industry. With these results, an analysis with a corresponding discussion was conducted to comprehensively illustrate the development of the industry to current and future unmanned store retailers.

\section{Sustainability analysis of the unmanned stores' concepts}

Currently, there are three pillars of sustainability impacts which include environment, social, and economic; and a possible fourth: human health (Hakovirta and Denuwara 2020). A literature review of existing research on the impacts of the food industry was conducted and critical analysis was made on how it could potentially be affected by the advent of unmanned grocery stores. Unfortunately, there are only a few academic articles solely on unmanned stores, and therefore, the authors connected the negative impacts of the food/grocery industry to the impact of unmanned stores' business models. These negative factors can be circumvented by introducing several new technologies that are targeted specifically towards mitigating any negative externalities. The findings from this review and analysis were divided into the widely accepted three pillars of sustainability.

According to the National Resources Defense Council, $40 \%$ of the food produced in the United States goes to waste and is not eaten (Gunders 2012). This translates to about $\$ 218$ billion worth of food that the nation wastes every year (http://www.foodi ndustry.com, 2019). In addition, in-store food losses in the United States totaled an estimated 43 billion pounds in 2008, which is equivalent to 10 percent of the total food supply at the retail level (http://www.foodindustry.com, 2019; Hazimihalis 2018). Because one out of seven families in the United States are food insecure a 10 percent loss is a significantly high number (Hazimihalis 2018). The USDA (United States Department of Agriculture) estimates that supermarkets lose \$15 billion annually in unsold fruits and vegetables also in 2005 and 2006, annual supermarket losses averaged 11.4 percent for fresh fruit and 9.7 percent for vegetables (Buzby et al. 2009). It has also been estimated that on average super-markets daily discard $\$ 2,300$ per store worth of out-of-date food (U.S. EPA Report 2016). Some grocery stores have come up with innovative ways to reduce food losses. In 2016, the EPA (Environmental Protection Services) stated that one of the ways to reduce food 
losses in grocery stores is to create discount shelves for near-to-expire or slightly damaged food (US EPA Report 2016).

Grocery stores need to constantly be innovating to solve some of these challenges that exist in the traditional food business value chain. The fast-paced technology developments, especially related to digitalization, enable the reduction of excess inventory and the associated risks on perishable items going bad before they are processed through the intelligent warehouse management systems (http://www.foodi ndustry.com, 2020). However, these technologies are only partial solutions and new business models are needed to make a true impact on food waste reduction. One business model innovation that could affect food waste is the unmanned grocery store concept. The environmental sustainability aspects of unmanned grocery stores are the food for unmanned stores that could be sourced through local farmers and the dynamic pricing model which helps decrease food waste.

Traditionally business models prefer items with longer shelf lives and thus defers more localized food offerings that may have shorter shelf lives. However, with the unmanned stores' concept, the shelf life of a product is less important because almost all products would be sold through the dynamic pricing system. It is important to examine the disposal rate of food in stores and how that applies to unmanned stores. Chung and $\mathrm{Li}$ reported earlier that increasing the shelf life of a product decreases its disposal rate (Chung and Li 2010). They compared two types of dynamic disposal rates (D1 and D2) with a fixed pricing rate. D1 referred to a dynamic system with a fixed shelf-life while D2 referred to a technologically advanced dynamic system that tracks the product's temperature and remaining shelf-life electronically (Chung and Li 2010). Through their results, they found that a more advanced dynamic pricing system would be $10-15 \%$ more efficient in reducing food waste. This is an opportunity to show that a dynamic pricing approach with improved shelf-life accuracy would generate a more positive impact on retail operations productivity to achieve higher profits and reduce waste compared to the approach without support from the shelf-life tracking information (Herbon and Eugene 2017).

This methodology allows items that are closer to their expiration date to be priced lower than identical items. Local farmers would benefit from this because shorter shelf-life items would still be able to be sold compared to their longer-shelf counterparts. As such, retailers can develop relationships with local farmers because their items would be considered higher-tier items than longer-shelf identical items due to their freshness and closer logistical proximity to the store. There are several sustainability aspects to this. One is the creation of an economically viable production system for food in a localized environment where there is ecological integrity and social justice (Feagan et al. 2004). The other is a technical aspect of the environmental impact of food transport when unmanned stores use local food systems instead of global ones to serve customers. Since unmanned stores have a smaller physical footprint compared to general grocery stores, an appropriate supply chain transport system contributes less harmful emissions to the environment because there are fewer goods to source and the goods sourced are from local systems. Dunne et al. (2011) noted a move towards local food by sellers of produce due to the increasing demand of such compared to non-local food by consumers. According to that research most consumers were documented to be willing to pay a premium for local food-this 
finding supports the positive economic benefit of going the route of local vs global food sourcing systems (Dunne et al. 2011). The use of shorter distance transportation, coupled with the use of smaller vans instead of larger trucks may also be additional benefit from Life Cycle Impact Assessment (LCIA) perspective.

Operational excellence and cost reduction mainly in staffing are the driving forces for unmanned store concepts. Due to this, the primary concern many have about these stores is that they will deplete jobs for the millions of cashiers that work in convenience stores. This is a valid concern, however, new roles in staffing may be created as well. Many conflicting studies discuss whether automation, robotics, and technologies will increase or decrease overall employment levels. What is agreed upon is that results differ for different industries as in for some, automation creates jobs and for others, automation creates job losses (Bessen 2019; Begley 2019). In the event of job loss, because automation is disruptive, training must be provided (by either corporations or public policy) to help workers transition from industries, occupations, and regions to ones that are growing and have a better employment outlook (Bessen 2019).

To elaborate, at Amazon Go, customers saw employees walking around the store checking for IDs at the wine section, greeting customers, making salads, and much more (Wilkie 2018). Additionally, owing to the self-checkout systems, the employees can use their free time to restock the shelves, receive products, or advise customers, which in turn facilitates the companies/retailers to make use of their employees more efficiently to gain productivity. Cleaning and maintenance of these stores also require additional labor and the creation of these jobs in rural communities is a valuable sustainability effect of unmanned stores that goes beyond the dynamic pricing impact on society. Ultimately, traditionally customers in the grocery stores usually look for contact, advice, and service and this can only be provided through physical retail store environments. Hence, while human labor in retail stores might get decreased, it will not be fully eradicated due to the retail experience that only humans can provide. Pop-up retail stores that are mostly unmanned will still require humans as either managers or as customer service representatives of an online service located at the retail location. This would increase higher-paying retail jobs (Farzan 2019).

Low overhead costs for unmanned stores are attractive from an expansion perspective because these stores can be located anywhere. The only constrain is the ability to connect to the supply chain. There is a large potential for these stores to be located in rural areas where small grocery stores are few in numbers and slowly going out of business due to high labor costs. In these rural areas, most people have to travel large distances to reach a grocery store and so locating an unmanned store can potentially be beneficial for the company operating the store or to the local community by itself. In most countries, there are still large amounts of rural areas whose technology has yet to be fully adopted-as such, unmanned stores can potentially serve as the first step for these areas to be digitalized since it does not require a huge amount of technical know-how to use an unmanned store. Other than rural areas, the unmanned store has the potential to grow in urban areas due to the increased population of urban commuters in metropolitan cities who value convenience and efficiency (Ilijason 2020). 
Limited in-person service saves on labor costs which helps the stores be located in places that have less population or traffic. Smaller communities with diminishing populations are having an increasingly hard time attracting new residents, especially when there is no grocery store in place nearby. Consequently, local access to food and groceries, in general, can be considered as a utility that is necessary for a community to exist (Webb and Naselli 2007). The reason that grocery stores are disappearing from rural areas is because of labor costs and low traffic. Cashiers are expensive to hire when there are only a few customers attending the store each day (Wasteless wants to help grocery stores waste less food using dynamic pricing 2017). On the other hand, supermarkets are capable of having long hours and low prices because of the high demand for goods in their stores. This makes it hard for small-town grocers to compete with the larger ones when most of their customers have decided to go to the city to do their shopping instead of going to their local stores. With unmanned grocery stores, it can be possible for a community to open a store with the sustainable goods and necessities they want for reasonable prices and opening hours that are flexible. Local producers and small businesses can then be better connected to the value chain of the unmanned store operator and the store can turn into a high-tech "farmers market". This can benefit the social fabric of rural communities.

\section{Dynamic pricing strategy for sustainability}

Revenue management can be considered as the umbrella covering different pricing strategies. The concept of revenue management is widely defined in literature as selling the right product to the right customer at the right price; aiming to maximize the profit, through market demand forecasting and optimization of price and inventory (Herbon and Eugene 2017). Dynamic pricing is a new pricing strategythat can be considered under revenue management. Using this methodology retailers change the price of the product based on supply and demand using for example Wi-Fi connected e-ink price tags (Nayak et al. 2015). These tags are connected to RFID systems that can assess various factors involved in store-buying patterns, such as demand for the day and location of the store and change the prices of the items based on these results. The dynamic pricing strategy that is associated with these tags meets the needs of individual customers by continuously adjusting prices to meet their needs. The use of dynamic pricing can affect profits negatively or positively. By reducing prices of certain items, there may be ultimately more buyers; however, if higher prices are received well, consumers may be prepared to pay more for the same product. Both instances benefit the retailer well, however, what is important is to know which system to use in which scenario.

Dynamic pricing is also used in cases where management would be alerted when a store is running low on an item or if items have been on the shelf for longer than anticipated (Zhu et al. 2018). In the first case, the item would be priced higher, and in the second, the item would be priced lower. And if the dynamic pricing model finds out that a stock is running low, the back-end solution will offer feedback to the headquarters for replenishment. This will also enable the operator to come 
up with the best-selling lists to cater to consumers' tastes. Dynamic pricing has the potential to essentially increase revenue by maximizing the profits a store can make from each customer, however, it can also cost a retailer if prices change too often because not only will it cost them more to inform their customer, but it might also upset customers who have certain expectations of price consistency for a certain selling period (Wang and Li 2012).

A major effect of dynamic pricing in the unmanned stores' environment is to decrease the amount of food waste generated by each grocery store. Millions of food items get thrown away each day after a grocery store closes because it has either reached or closely reached its expiration date. The dynamic pricing concept is a highly potential approach to give an incentive to the consumers by discounting food items that are closer to their end-of-life date. This happens through the attachment of RFID tags or labels and e-ink displays in each item or the shelves of the items to continuously update prices based on the expiration date or the number of items in inventory (Treuhaft and Karpyn 2010). RFID tags/shelves can also track inventory levels automatically every 15 min by transmitting sales data to an RFID reader. The result to decreasing inventory level through decreasing the price of items closer to the expiration date is straightforward; Items that would usually be thrown away would get a better chance in finding their way to their consumption purpose rather than bypassing it and with no consumer-use moving the item from cradle to grave.

When unmanned stores discount prices of items that are closer to their expiration, it creates a large impact on lower-income communities who usually have less access to healthy and fresh foods due to the intrinsic high prices. To drive equity and health-related benefits of fresh food, unmanned stores and dynamic pricing could potentially be highly beneficial to low-income communities (Treuhaft and Karpyn 2010). With dynamic pricing, all the consumers in the market-including lowerincome, minority, and rural communities - would be able to get local farmers' items that are nutritious for them, and in return, they could better support the local farming community. This is a true sustainability benefit because the model can sustain itself efficiently if implemented while benefiting society at large.

Dynamic pricing is not a perfect solution. To keep the profitability of these stores attractive, the issues with unmanned stores preferring to carry processed food products need to be solved. The fresh products have much higher margins, and they differentiate unmanned stores from simple vending machine-type operations. Also, fresh food connects to the systemic economic benefits of the local community and thus the consumer acceptance. Two other issues with dynamic pricing are 'negative customer sentiment' and price wars (MENA Report 2016; Le and Liaw 2017). Negative customer sentiment involves the perceptions a customer has when they receive a price for an item that they expected to be priced lower. Not only does this erode customer trust in a brand, but it can also reduce the interest as consumers may view prices as being changed too frequently. Price wars involve different retailers gouging the price to compete with a different retailer. The traditional retail price matching is a part of dynamic pricing where the prices are adjusted to meet other retailer's prices to attract more customers and increase sales. In unmanned stores, negative customer sentiment and price wars will not be as high of a concern because the product being sold is mostly food. One reason for this is that because the price of 
the food would be dependent on its expiration date, the retailer would not be accused of changing the prices without cause or explanation. To fix this, retailers must make clear to customers that the dynamic pricing system is only based on shelf-life features and accurately identified product deterioration rates (Wang and Li 2012).

\section{Unmanned Store Concepts and Business model}

The omnichannel experience is valuable in many retail environments such as apparel, healthcare, and even government; however, it is hard to be utilized in one of the biggest retail areas: food. The total online and offline grocery retail service sales in the US account for over 1 trillion USD; in contrast, the revenue for all apparel retailers in the US is only 342 billion USD (Statista 2020). Of the 1 trillion in total food sales, \$31.39 billion is from online sales (Statista 2020). IR Research found that $80 \%$ of grocery customers have never ordered groceries online but the trade organization, the food marketing institute (FMI), expect that by $2022,70 \%$ of consumers would buy at least some groceries online (Internet Retailer Research Online Food Report 2018). Consumers are getting more comfortable with online shopping which is why it is expected that the online grocery market will reach $\$ 117$ billion by 2023 (Magana 2019). A 13\% CAGR (Compound Annual Growth Rate) is expected by 2022 for online grocery sales, much exceeding the $1.3 \%$ CAGR expected for instore sales (Magana 2019). While it may seem enticing to enter the online grocery market, established grocery players in the market, such as Walmart and Kroger, are increasingly competing with each other in an attempt to grab a larger market share. There exist a lot of barriers for entry for retailers to transition into an online model (Magana 2019). First and foremost is the issue of logistics and last-mile delivery costs so there needs to be internal expertise and financial support to design and implement leading-edge technology to give themselves a competitive advantage (Internet Retailer Research Online Food Report 2018). However, there are several ways these established players are breaking these barriers including Amazon using their fulfillment centers and pioneering e-commerce model and Walmart using its large brick-and-mortar footprint to its advantage (Magana 2019).

Food e-commerce comes mainly in the form of shop online-deliver to door; or shop online-pick up at store. In the first case, there is a subcategory called meal kits that belong to retailers that only have an online presence and who ship ingredients to meals in one package to a customer's door (Heard et al. 2019). In the second case, brick-and-mortar retailers try to attract consumers who value convenience and speed over the experience of shopping in-store (Heard et al. 2019). One of the main issues with online grocery shopping is that like most other e-commerce trends, the adoption of online groceries has mainly revolved around packaged goods like dry pasta or cans of beans and strayed away from more personally selected items, such as fruits and vegetables (Internet Retailer Research Online Food Report 2018). This leaves a large section of grocery sales untouched which hinders the growth of the online grocery field quite a lot.

In addition to meal kits, there are now food delivery models, such as Doordash, Uber eats, and Grubhub, that are a mixture of physical and online food retail. By 
partnering up with restaurants near the location of a customer, these delivery companies provide hot meals to the customer in a fast and efficient way. While both food delivery and ingredients delivery concepts apply also to meals, it is not reasonable for many consumers to subscribe to individual food products to be purchase or delivered online due to their price. In addition, busy young professionals are an increasing consumer category that also demands flexibility in deliveries and purchasing. Scheduling of delivery is not always the most attractive alternative. The answer to this lack of full digitalization in food retailing comes in the form of the unmanned store that provides various food items in a $24 / 7$ physical store that a customer would mainly interact with using digital channels. The unmanned store is a cashier-less store that is equipped with machine automation, IoT, facial recognition, and other sensors that monitor shoppers where the shopper can pick up an item from physical shelves, walk out the door with it, and then be automatically charged for it (Chan, et al. 2019).

In theory, unmanned stores can reduce labor costs and therefore, retail prices for customers (Zheng and Li 2018). The facial recognition software used in these stores can also capture the facial expressions of the customers (such as satisfied, neutral, and dissatisfied) to gage their experience in the store (Zheng and Li 2018). Unmanned stores are divided into two categories: fully automated and semi-automated. Fully automated stores have no human operating the store; henceforth, all cleaning, stocking, preparing food services would be done by a robot. In semi-automated unmanned stores, the store is mostly unmanned except most of the behindthe-scenes handling of products would be done by a human. In this paper, unmanned stores will be defined as semi-automated convenience stores. Semi-automated stores in the global unmanned convenience store market had a market share of $91.6 \%$ in 2019 and were worth US \$61.81 million (The Insight Partners Report 2020). This segment is expected to continue its dominance till the near future where it will account for around $80.1 \%$ market share by 2027 and worth US $\$ 1.3$ billion (The Insight Partners Report 2020).

One of the forms of unmanned retailing is unmanned shelves, and the intelligent container is an inevitable evolution of unmanned shelves. Unmanned stores can use AI-operated cameras for completely automated shelves that monitor inventory levels in the shelves. For example, if the amount of shrimp in a freezer goes low, a staff would automatically be notified and would then go to re-stock that item (Jederman et al. 2014). On the other hand, unmanned stores like Amazon Go, outfitted with the latest wireless IoT technology, are a more enhanced version of unmanned shelves. These stores make flexible, independent shopping possible through their 'just walk out' technology (Solana et al. 2017). The benefits of unmanned stores are composed of lower overhead costs after sales and cashier jobs are eliminated, the ability to collect consumer data through online checkout via a smartphone app, and more efficient retail management by localizing product inventory and merchandising based on individual stores.

One problem that might arise is customers' unwillingness to use an unmanned store because they view it as a glorified vending machine. However, while the vending machine can be seen as a sort of automated retail, the inclusion of the online purchasing ability is what makes unmanned stores a truly innovative concept (Zheng 
and $\mathrm{Li} \mathrm{2018).} \mathrm{Another} \mathrm{issue} \mathrm{is} \mathrm{that} \mathrm{most} \mathrm{unmanned} \mathrm{stores} \mathrm{carry} \mathrm{only} \mathrm{long-lasting}$ products over goods with expiry dates. This may impact the profitability of the business model as in Japan and China, it has been reported that the gross margin on long-lasting processed food is only about 25\% (Murayama 2019). Comparing that to the gross margin of fast and fresh food which is around 40-50\%, this implies that the type of food matters to store income and that fresh groceries are better for this (Murayama 2019). It can be stated that a store with only fast-food items looks more like a vending machine and less like an actual store for daily shopping. Additionally, most retailers do not use their data enough to learn more about consumer habits, and thus the full benefits of digitalization are not explored by the retailer (Aly 2020).

\section{E-commerce supply chain vs. traditional supply chain}

Growing competition between the online players is stimulating traditional retailers to reorganize their store networks in many aspects; from design and layout to size and scale (Bell et al. 2015). The rise of e-commerce has driven the development of unmanned stores as they cannot be supplied by traditional supply chains. The highly limited staffing or even zero staffing will be operating the day-to-day affairs of unmanned stores, all order fulfillments requests need to be automatically connected to fulfillment centers without any personnel in the process. Furthermore, traditional supply chains would not be able to handle the small number of orders relevant to unmanned store business models. Traditional supply chains are useful for bulk orders, but unmanned stores are small enough that they do not require bulk orders to fill their needs; henceforth, these stores need e-commerce to supply them with any item that goes below their safety stock levels. The logistics of shipments are therefore implemented through services, such as FedEx, UPS, or the U.S. Postal Service. This logistical setup demands RFID tags and sensory systems and big data analytics to track and manage orders. With all these developments in commerce, the number of supermarkets is expected to decrease because of the rising popularity of convenience stores, discount stores, and online shopping, signifying that average store size could shrink by $\sim 35 \%$ in the coming decade (The Insight Partners Report 2020). It can be stated that this would help in the growth of e-commerce in the future due to e-commerce players expanding their offline business operations to seize market share; further, this would fuel the rise of smart grocery stores.

As the paradigm shift in retail and commerce is related to digitalization and big data analytics capabilities, it is not necessarily the size of the store that makes it a better candidate for e-commerce. The key is more in the technological advancement of the pricing system and order fulfillment system required by such stores. Utilizing a smart and dynamic pricing model and automatic fulfillment system, the store can use an e-commerce supply chain instead of a traditional supply chain. Looking at sustainability benefits of the use of the small order fulfillment systems through e-commerce supply chains, a good example is that local food producers can benefit from small orders as local producers are more relevant and equipped to provide highly profitable fresh produce and other products rather than the large global producers. From a value chain and value capture perspective, the global players will not 
see as much profit in supplying small orders to smaller size stores more frequently. In many cases in grocery unmanned stores prepared foods would be a major portion of the products sold, therefore the fulfillment of these orders needs to be very quick and reactive to the automatic orders sent through e-commerce order platforms.

\section{Value chain of the food network}

The value chain of the food network is important to understand when analyzing the sustainability impacts and future direction of the unmanned store concepts. Figure 1 illustrates the food value chain we are using as the framework for our analyses. The value chain starts with the producer network which includes agricultural processes, initial packaging, and logistics, and then the item goes to the manufacturer network which processes the final food product and packages it for wholesale, store, and consumer use (primary, secondary and tertiary packaging). The third network is the wholesaler or warehouse network which involves the storing of the food and inventory management of the products. The fourth step is the delivery network which is responsible for the logistics for the product from the warehouse to the store and the final network is the grocery store which is the location where customers get access to individual food items. As with all value chains each step includes an internal process that adds value to the chain. These internal dimensions have not been evaluated in this paper.

A more thorough analysis of the value chain shows that the traditional value chain in the food industry is long and separate with limited interaction between the networks. In comparison, unmanned stores' value chain is more interactive and significantly shorter. For example, if local farmers' produce is used, the value chain would decrease because most fresh food items could potentially advance from the producer network to the store more efficiently, partially, or even eliminating the manufacturing, warehouse, and delivery networks. Manufacturing of fresh food could be done by the producers including growing the produce and manufacturing the food and even packaging the item. The traditional large-scale warehouses would not be

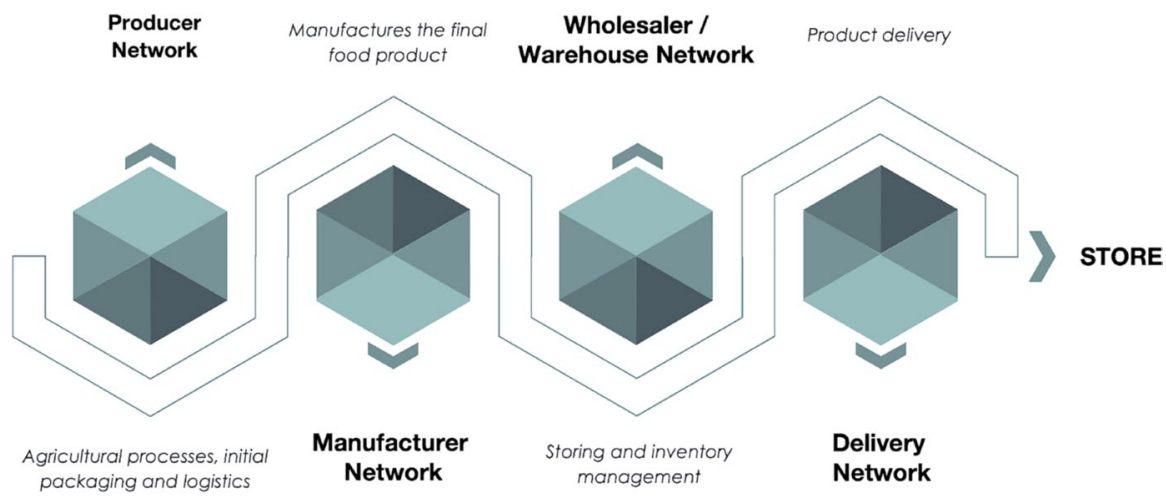

Fig. 1 Food value chain and networks 
needed because the producers would only store the food for short periods before delivering the items to the store themselves. Essentially, the producer network would grow and increase its value capture in the value chain and as a result, the economy of small communities would be benefiting as the producers are local farmers.

Looking systemically at the impact analysis of changing a value chain, there will always be winners and losers. In this case, the manufacturers and warehouses would lose business while the delivery network would have to change from wholesaler to store, to producer to store. Furthermore, since these stores are cashier-less, either the store would be responsible for stocking the shelves, or the delivery network would have to take ownership of that process. In summary, retailers need to rethink their value chain and who adds value to their business to generate profit from unmanned stores.

\section{Methodology}

The unmanned grocery store ecosystem is comprised of a variety of players. The major end-users in this article are defined as retail businesses that provide groceries, confectionery, snack foods, and soft drinks. A questionnaire was developed through Qualtrics to research the current direction and speed of the business development of the unmanned stores' concepts. This included the identification of the existing economic barriers for unmanned stores' expansion and the sustainability benefits for these types of stores. Baumgartner (2011) states that there are two aspects of sustainability science: one based on strategy and the other in solid scientific principles. We chose to conduct a questionnaire as our research tool on the current topic through a strategic lens with the intent to begin the conversation on unmanned stores. All participants were identified via LinkedIn and messages were sent to their emails containing the survey link. Company websites were verified to make sure that they were doing appropriate work and insight to the unmanned stores' value chain. The data were then analyzed with excel to find connections within the data set; conclusions were made after the analysis and are discussed below.

The questionnaire was limited to 11 close-ended questions to ensure a $100 \%$ response rate from the participants which we were able to gather. The questions were formulated in an unambiguous and straightforward manner which included multiple-choice questions, ranking choice questions, and two open-response questions. A 2019 research study by Popescu and Popescu on sustainable finance carried a similar questionnaire out to examine corporate social responsibility in Romanian businesses and was able to establish strong connections between corporate social responsibility, intellectual capital, and performance. With the use of our questionnaire, we intend on obtaining results that can show a better picture of the innovation and sustainability of a novel business concept-unmanned stores.

In total, 10 companies representing the value chain were identified by an extensive web search as key players in the industry and invited to participate in the anonymous questionnaire. The answers were the opinions of professionals in corporate business development roles within both major and emerging players in the global market for unmanned stores. The individual's background was selected by closely 
researching their professional history through LinkedIn and checking their ability to answer the questions of the survey. All relevant geographical areas were included in this study (North America, Europe, Asia Pacific (APAC), and the Middle East). 11 questions were introduced, and the answers were critically analyzed (Table 1).

\section{Results and discussion}

As illustrated in Fig. 1, most of the industries that are currently being expanded into unmanned stores concepts include the food industries that are comprised of grocery, coffee, and prepared foods. The reason we decided to examine these segments for expansion is that most companies are only interested in the food industry while some are taking the steps to expand into other industries to stay competitive (Global Datapoint 2018).

\section{Industry expansion}

In Fig. 2, the black bars represent current expansion, the gray bars represent future expansion, and the white bars represent no expansion. Grocery is the industry that each company either is already in or plans to be in. Looking at our results none of the interviewees selected that they had no plans to expand towards that industry. Segment "Coffee" is the cafes that serve coffee and prepare food. Interestingly, the coffee industry, if unmanned stores expand into, will need to be fully automated because, in current café business models, each cashier also provides the service, henceforth, if cashier jobs are eliminated, service jobs will be eliminated along with it. Due to this, service jobs will need to be replaced by robots and automation to fulfill the types of service required in cafes. In this study, prepared foods do not include restaurants because restaurants include a non-replaceable service such as cooking for large quantities at one time. However, "prepared foods" in small convenience stores can become a part of the automated service provided in unmanned stores because these types of food will be prepared off-site and then frozen before being delivered to convenience stores in small orders. Or perhaps produced in local produce or other suppliers' facilities.

"Hobby stores", "flowers and plants", and "home décor", are the segments that companies are currently least interested in planning to expand unmanned stores business concepts into. Hobby stores include stores like Michaels and Home Depot which carries materials for knitting, painting, building, and others. Part of the reason that these companies are not planning for expansion might be due to the retail experience customers desire when they enter hobby stores. They most likely want to explore the offerings of the store while figuring out what else to buy. This is the same with home décor where the customer is specifically in the store to browse and not immediately buy. However, with stores that offer staples, such as groceries and prepared foods, most customers are there for certain specific products that they most likely had planned for before entering the stores. And so, the quicker they get in and out of the store, the more the 
Table 1 Questions asked in the survey to participants from the value chain of Unmanned Stores

Question 1 Estimate the expected benefits from unmanned stores for your company over the next five years?

$\%$ Additional revenue

$\%$ Reduction of operations

$\%$ Efficiency gains

Question 2 How would you classify your company's current status on unmanned stores business development (regarding your role/position in the value chain?

Initiation phase (feasibility study)

Planning phase (business case under preparation)

Execution phase (actively doing business)

Monitoring phase (established unmanned store, and collecting and analyzing data)

No activities

Question 3 Rank the value chain benefits you see as most impactful in unmanned store concepts with \#1 being most impactful

Big data / analytical support to the supply chain (e.g., local produce faster to stores)

High-performance warehouse management

Value chain integration

New digital business models

Customer access, sales channels, and marketing

Improving relationships and value chain collaborations

Question 4 How will unmanned stores deliver revenue, cost, and efficiency gains? Rank in the level of importance (5-most important; 1-least important)

Real-time quality control based on Big Data Analytics

Flexible and customer-tailored offering (ex: vegetarian food and food free of allergens)

Track-and-trace of products for better inventory performance and reduced logistics

Digitization and automation of processes for smarter use of human resources

Real-time customer feedback and satisfaction

Localization and stores being located closer to customers

Question 5 Rank the sustainability benefits you see in the unmanned stores? \#5-most important

Eliminating food waste due to accurate inventory levels and dynamic pricing models

Decreased transportation due to unmanned stores' ability to carry food from local farmers

Decreased transportation from consumers due to unmanned stores' ability to be located closer to customers

A higher educated workforce is needed for the digital management of unmanned stores. Higher paid employees in stores

Grocery store survival in rural areas due to the reduced cost of operations

Affordable prices for rural and low-income populations with better access to healthy and fresh foods

Question 6 Rank the areas where the company will use data analytics gathered through unmanned stores in the next five years? \# 5-most recent benefit expected

Improving customer relationships and customer intelligence along the product life cycle Dynamic pricing attracting customers with price point awareness (e.g., food expiry date and price)

Building a customer-focused supply chain

Basing product/service development on customer specifications

Input to new business development

Sustainability benefits - waste reduction with online awareness of best-before-dates 
Table 1 (continued)

Question 7 Rank the biggest challenges in building digital operations capabilities for your company's role in unmanned stores? \#5-biggest challenge

Digital operations vision and support/leadership from top management

The economic benefit is not clear

Investments required are not clear

Overall concerns in data security and privacy

Insufficient talent in the organization

Lack of standards for digital operations

Availability of basic digital infrastructure

Difficulty in finding suitable business partners

Question 8 Select the timeline of expansion for the stated industries. Choices are spread between currently, in five years from now on, and not planned for right now

Electronics and games

Apparel and accessories

Makeup

Home décor and materials

Hobby stores (knitting, sewing)

Grocery

Coffee

Prepared foods

Flowers and plants

Toys

Pet supplies

Books and office supplies

Question 9 What are your company's current and future investments into unmanned store development and operations? (investment as a percentage of annual revenue)

Current $\%$ of net sales

Future (five years from now) $\%$ of net sales

Question 10 Please state the return on investment period (ROI) you expect from your company's unmanned store concept investments?

Question 11 Which regions are currently most important for unmanned store expansion (5-most important; 1-least important)

North America

South America

Asia Pacific

Europe

Middle East

Africa

customer is happy. Continuing with this conjecture, surprising is the number of companies that do not see the expansion of unmanned stores to the "flowers and plants" segment as lucrative. One reason may be due to the fact of the quality of service that raising plants require. However, this study defines flowers and plants as small convenience stores that carry flower bouquets or little plants/seeds in a store similar to a vending machine. These stores do not require service because the flowers would have already been gathered off-site and the store will only serve the product and no service. The floriculture industry is a global market and is large and increasing. Also, their gross margins are relatively high. The self-service levels have however steadily declined in the past 10 years. As such this industry can have the potential for expansion with unmanned store concepts 


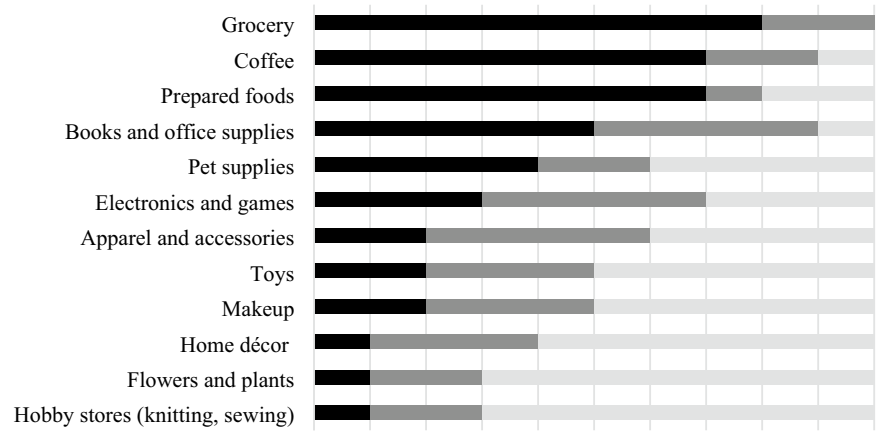

$\begin{array}{lllllllllll}0 \% & 10 \% & 20 \% & 30 \% & 40 \% & 50 \% & 60 \% & 70 \% & 80 \% & 90 \% & 100 \%\end{array}$

Fig. 2 The industries planned for expansion in the unmanned stores' space. The dark bars show the current situation, and the lighter bars are the 5-year target

as there has been an increasing number of airports that carry automated flower vending machines which can easily be placed in such high traffic environments as airports. Similar locations, including harbor terminals, train and bus stations, libraries, and museums, are likely to support automated stores if the location has the proximity or traffic for the desired customer base.

According to our questionnaire, the four areas that interviewed companies see the most potential segments to expand unmanned stores into during the next five years, are "books and supplies", "electronics and games", "apparels and accessories", and "toys". These all are specific markets that connect to certain demographics and psychographics. And some correlate with a higher income population.

\section{Investments}

In our study, we were also interested in how high the investments the interviewed companies were looking at for unmanned stores currently and in five years from now (investment as a percentage of annual revenue). This shows the growth and expansion trends moving forward. For this question, 8 out of the 10 companies studied answered this question. The average amount of investment reported currently is $17.1 \%$ of net sales (with a median at $20 \%$ ). This number is relatively high for investments in a new business concept, however, many of the companies that answered are currently in the execution phase of unmanned stores' expansion (operating stores) or following that which in our questionnaire was categorized as the monitoring phase (operating and collecting data from operations). The average amount of investment that was found to be invested in five years from now was $20.4 \%$ of net sales from the 7 out of ten companies that answered (median being at 5\%). This means an increase of $16 \%$ over five years. According to our study also the average expected payback period for these investments was found to be 2.5 years (with a median of 2.75 years). 
Table 2 Percentage increase of the amount of additional revenue, reduction of operations, and efficiency gains from unmanned stores
Estimate the expected benefits from unmanned stores for your company over the next five years?

\begin{tabular}{ll}
\hline Additional revenue & $14 \%$ \\
$\%$ Reduction of operations & $15 \%$ \\
$\%$ Efficiency gains & $21 \%$ \\
\hline
\end{tabular}

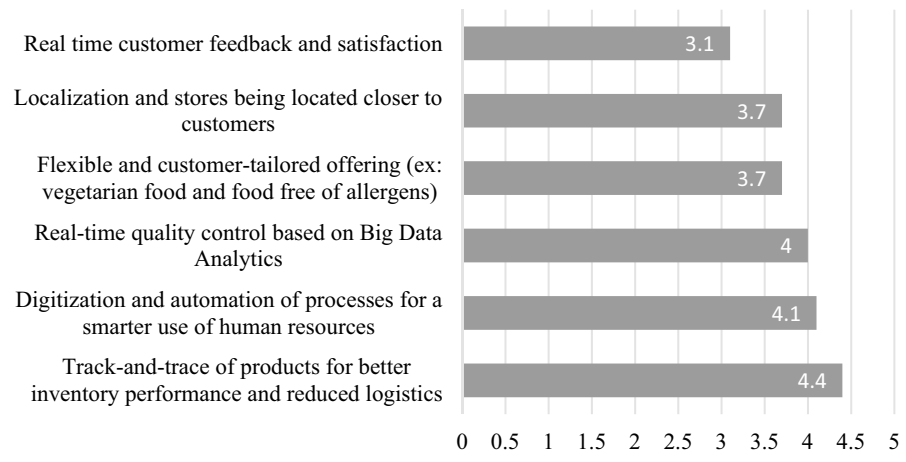

Fig. 3 Ranking of which factors were most important for the companies' revenue, cost, and efficiency gains

\section{Financial benefits of unmanned stores}

Continuing to investigate the future economic potential of the unmanned stores' concepts, we asked the interviewees to estimate the percentage increase of the amount of additional revenue, reduction of operations, and the efficiency gains in the next five years. The results (detailed in Table 2) show an average estimate of $13.9 \%$ in additional revenue, $14.8 \%$ in reduction of operations $20.8 \%$ in efficiency gains. The largest benefit found in 9 of the 10 companies surveyed was the percentage of efficiency gains. It is worth stating that reducing the cost of operations or increasing revenue can add to a company's net profit figure, but it may not necessarily improve the company's net profit margin (Maverick 2020). The results in Table 2 can be concluded to mean increased revenue and decreased operations cost essentially drives increased efficiency of a company that is expanding into the unmanned stores market.

\section{Revenue, cost, and efficiency gains}

Figure 3 summarizes which factors based on our interview are more important for the companies' revenue, cost, and efficiency gains. Tracking and tracing products is the most important factor, and this is related to the \% efficiency gains discussed above. By increasing inventory performance and reducing logistics required for 
operation, the efficiency of a company is increased. The second factor, digitalization, and automation of processes for smarter use of human resources are also related to efficiency gains. This helps make sense of efficiency gains and reduction of operations costs being the largest benefits of unmanned store expansion. Real-time quality control and location of stores are equally important for revenue, cost, and efficiency gains. Quality control affects the service and product delivered by each store which increases revenue, and the localization of stores also affects revenue. Interestingly flexible offerings and customer satisfaction play a minor but important role in revenue gain as these factors are ranked the lowest in importance.

\section{Value chain benefits}

The value chain benefits were investigated by looking at the most impactful benefits for unmanned stores in Fig. 4. Rank no. 5 is the most important with a rank no. 1 being the least important. The average rank for each factor is displayed above. Figure 4 shows that the interviewees ranked the most important as big data support to the supply chain which matches up with the most important factor for increased revenue, reduced costs, and efficiency gains: track-and-trace of products. Analytical support to the supply chain means, partially in unmanned store terms, that it is possible to track where a product is in the value chain and where it came from. This kind of information can help increase the sustainability of these stores by being more aware of where each product is coming from and what impact there is from each product. As such, the largest economic impact that exists in unmanned stores is the most important factor in increasing the sustainability of unmanned grocery stores. The least important impact is increased warehouse management performance. This could be because existing large companies currently have an established warehousing system that might already be highly efficient. Especially, large companies expanding into the unmanned stores' space would most likely utilize their existing warehouse system instead of building new systems for this specific purpose.

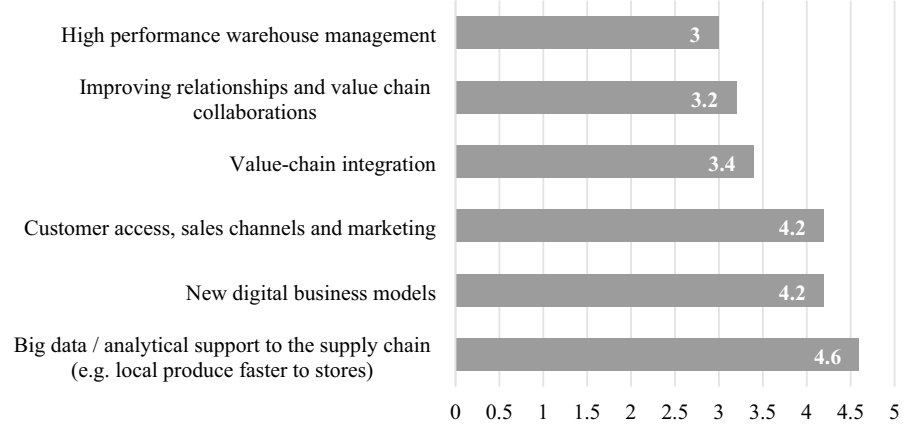

Fig. 4 The average of the interviewees' ranking of which value chain benefit is most important for the unmanned stores 


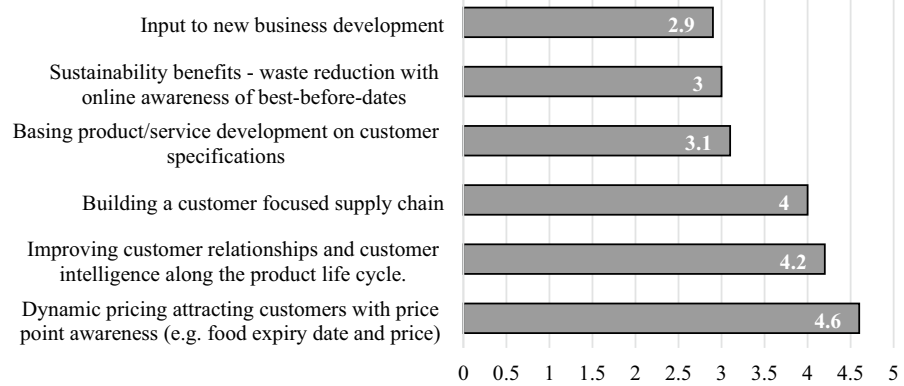

Fig. 5 Average ranking of where the respective companies will use the data analytics gathered through unmanned store operations in the next five years

\section{Data analytics use}

The use of data analytics and its importance to the companies in the next 5 years was surveyed and is reported in Fig. 5. Rank no. 5 is the most important with a rank no. 1 being the least important. While track-and-trace of products produces strong data analytics, this information is mostly used to build a customer-focused supply chain. Customer-Focused Supply Chain Management is a strategic approach that attempts to meet supply and demand to enhance customer's overall satisfaction with the goods the company offers. In this system, the approach will eventually improve the profitability of itself by reaching those satisfaction goals for not only the customers but also all supply chain partners (Madhani 2018). This is an interesting finding because Table 2 found that real-time customer feedback and satisfaction is the least important factor for increasing revenue and efficiency and decreasing operation costs. Overall, customer feedback and satisfaction are very important, however, gaining that data 'real-time' through data analytics decrease the profit margin of companies when compared to the revenue gains and the increased costs of transitioning to big data in the supply chain. The second important use of data analytics is dynamic pricing. This was the only instance that dynamic pricing was examined in the questionnaire because dynamic pricing through big data is still a relatively new model. However, it is clear that while it is new, data analytics could be used more efficiently in this area. Building a CFSCM (Customer-Focused Supply Chain Management) is highly and in combination with dynamic pricing can be effectively used to enhance the bottom line of a retailer. While it is considered less important than building a CFSCM, data analytics would serve a better use in dynamic pricing. Waste reduction with online awareness of expiration dates was based on our survey one of the least important areas in the use of data analytics. This area is a large factor of any sustainability analysis; however, waste management and data analytics seem to play a limited role in companies' sustainability strategies. The data in Fig. 4 illustrate that data analytics - the most important impact of unmanned stores in the value chain-is not used much for reducing waste. This is a discounted opportunity and may increase in importance when the sustainability strategies for unmanned store concepts are conceptualized. 


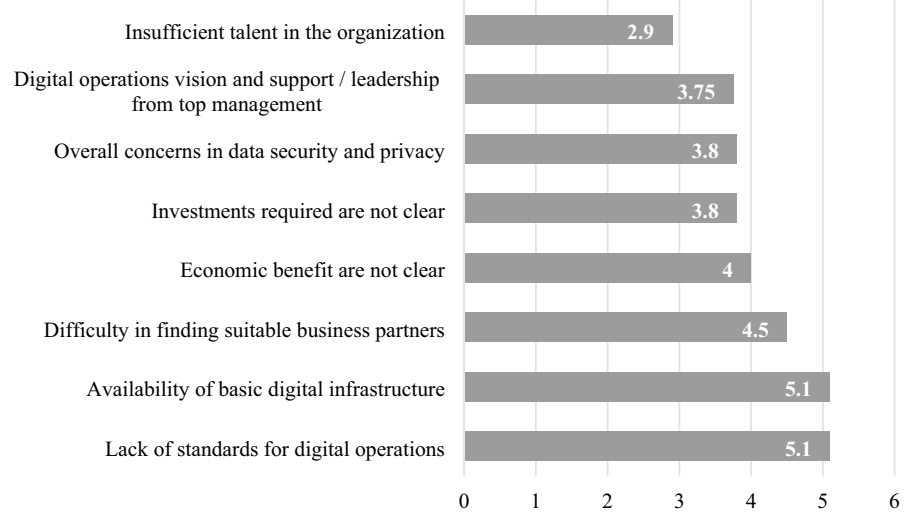

Fig. 6 Average ranking of the biggest challenges in building digital operation capabilities for unmanned stores

\section{Challenges}

Identification of the biggest challenges in building digital operations capabilities for the unmanned stores is critical and thus was part of the questionnaire (Fig. 6). Rank no. 7 is the most important with a rank no. 1 being the least important. Unmanned stores rely on a successfully operating digital infrastructure and therefore the top two digital challenges are not surprising. There need to be industry-wide standards that all unmanned stores can follow in their digital operations. Additionally, there needs to be a basic digital infrastructure available to all players. Both of these are based on our survey of the minimum requirements for unmanned store operations. These hurdles can and are currently overcome through the use of third-party companies that regulate the standards used for operation and investing in the four components of digital infrastructure: connectivity and transportation, storage and processing, services and applications, and terminals and devices (http://www.AIIB.org, 2020). Connectivity and transportation refer to the component manufacturers, storage and processing refer to the technology providers, services and applications refer to the network service providers, and the terminals and devices refer to the end-users that are the physical retail stores. The respondents stated that they understand the investments required by selecting it as one of the least challenges in building digital operation capabilities. Another interesting finding in these data is that the 'economic benefits are not clear' challenge is considered to be one of the highest-ranking challenges. This is a surprising finding because a majority of the respondents surveyed are in either the execution phase or the monitoring phase. The result implies that most of the companies that are already operating in the unmanned stores' space are doing so while not being sure of the economic benefits. Another very critical and challenging factor in the list of digital operations is in finding suitable business partners. This is because unmanned stores are a relatively new field, but more and more competitors are entering the market—by signing partnerships, contracts, 
joint ventures, and inaugurating new offices across the world, companies are trying to increase their market share and brand presence in this space (The Insight Partners Report 2020). While this may help in finding business partners for the value chain of these stores, it could also serve as a barrier of entry in finding partnerships for the players competing in the same industry.

\section{Dynamic pricing}

Figure 7 displays which sustainability impacts of unmanned stores that companies believe exist. Rank no. 1 is the most important with a rank no. 5 being the least important. The first and third-most important sustainability benefit occurs through the use of the dynamic pricing model. Not only do companies believe that it can eliminate food waste, but it can also help communities that lack access to healthy food. Dynamic pricing is a part of the digital infrastructure for unmanned stores using improved data analytics. Companies in this space also believe that unmanned stores would be located closer to consumers than the current version of grocery stores. The unmanned stores will use an e-commerce supply chain, and thus more job opportunities for the digitally educated workforce will emerge. This is however not agreed by the companies participating in the survey as they ranked the highly educated workforce lowest in the list. List for the sustainability benefits of unmanned stores included the decreased transportation from warehouses to the retailer because e-commerce will create a situation where only local farmers can respond to the small number of orders that will be created through a smaller-sized unmanned store. Either that or larger scale producers have to find ways to change their response method to automatic fulfillment orders from bulk orders to smaller-scaled ones. If local farmers become the dominant producer for unmanned stores, it will also increase the amount of a higher educated local workforce because the local farmers would have to improve their digital infrastructure and know-how to satisfy these types of orders.

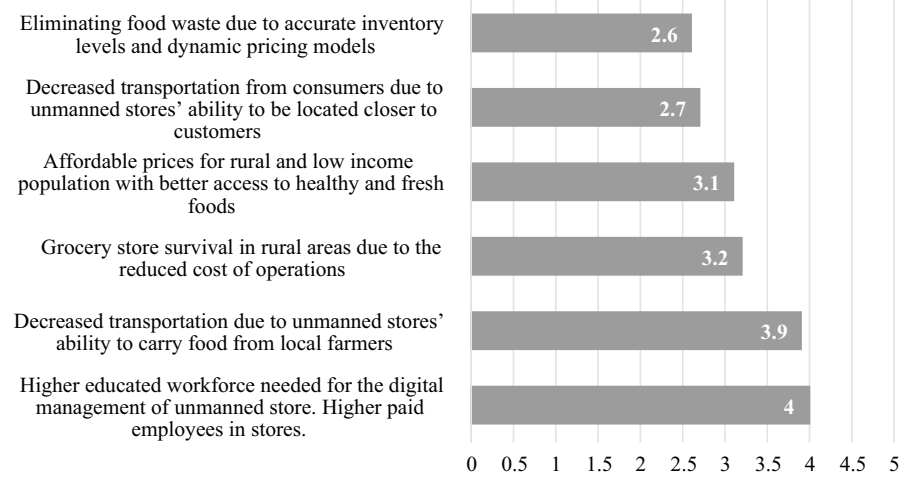

Fig. 7 Average ranking of the most important sustainability benefit that occurs through the use of the dynamic pricing model 
Table 3 Ranking of the geographical areas the interviewed companies were thinking of expanding their unmanned stores model into

\begin{tabular}{ll}
\hline $\begin{array}{l}\text { Rank the most important geographical areas to expand unmanned } \\
\text { stores concept into? }\end{array}$ \\
\hline 6 & North America \\
5 & Asia Pacific \\
4 & Europe \\
3 & South America \\
2 & Middle East \\
1 & Africa \\
\hline
\end{tabular}

\section{Geographical areas}

The lists in decreasing order, which geographical area is considered most important in unmanned stores expansion can be seen in Table 3. Rank no. 6 is the most important with a rank no. 1 being the least important. The most important economy for expansion is considered to be North America. Asia Pacific is higher than Europe because currently, as of now there exists an installed base of unmanned stores in APAC countries. Most of the market initiatives for expansion are currently observed in the Asia Pacific, North America, and Europe regions, which have a high potential for future market growth (The Insight Partners Report 2020). The unmanned convenience store market was dominated by APAC, which accounted for $61.7 \%$ in 2019 and will continue to dominate the market by 2027 accounting for $59.7 \%$ of revenue share (The Insight Partners Report 2020). Taiwan currently boasts of having one of the highest convenience store densities in Asia, with over 9000 stores, and these stores each contain the high potential to be automated and turned into unmanned stores (Zhu et al. 2018).

All the geographical areas listed in Table 3 should be considered individually in the strategies taken for expansion because research has found that cross-national differences exist in the diffusion process of innovation and technology, which unmanned stores fall under (Takada and Dipak 1991). In a cultural context, countries with homophilous types of communication are more likely to adopt technology than heterophilous (Takada and Dipak 1991). Homophilous types of communication exist in countries like Taiwan, Japan, and South Korea where the population is mostly homogenous with similar cultural and socio-economic backgrounds (Takada and Dipak 1991). Transfer of ideas may happen easier within alike populations rather than heterogeneous populations where the type of communication-heterophilous - and the population is more diverse.

The Asia Pacific Region includes some of the fastest-growing world economies, such as China and India. Along with that, Japan is the most technologically advanced country in the region allowing the development of new and better solutions in the region. To further improve their businesses, the companies in these regions are moving towards automation, thereby accelerating the growth of the convenience stores market in the region. Japan has the highest density of vending machines in the world partially because Japanese people tend to perceive innovation 
and technology as positive and amiable and because the busy fast-paced work ethics culture creates an opportunity for companies that can provide easiness, flexibility, and convenience in retail (Takada and Dipak 1991). Unmanned stores in the West are less of a commonality than in East Asian countries which could be attributed to the reasons discussed here. The retail environment requires constant innovation for retailers to stay competitive and consumers who are open to new technology that changes the current landscape. While the unmanned store may be more of a challenge to grow into a cultural phenomenon in the west for retailers, consumers play a huge part in its spread and retailers should not forget about their role when planning for expansion.

\section{Conclusion}

This article is the first one of its kind to start the discussion on unmanned stores. Based on our observations, there are no existing research papers that examine various dimensions of unmanned stores' operations outlook and growth. Currently, the digitalization of grocery stores has mainly revolved around online groceries. But profitability for online groceries can only be achieved by several factors. First, companies need to reduce the amount of human labor necessary to pick and prepare orders (Magana 2019). One way to accomplish this is by automating parts of the picking and order assembly process. To drive the adoption of online grocery, grocers need to build a reputation for having reliable employees who select quality goods. This is not an issue with unmanned stores because shoppers will be doing the traveling to stores and picking their items. Furthermore, customers can be assured that they are picking the best fruits and vegetables over having an unknown person picking questionable items for them. The automation of these stores revolves around the checkout process and item handling by staff process.

Looking at the online groceries it is important to note that to achieve profitability, the stores only need to carry the cost to operate the level of service that is necessary to meet the demand. With unmanned stores, there is a limited amount of labor required for the store to operate, because most of the staff in stores are cashiers, and cashiers are not needed, by definition, in a cashier-less store. This reduced labor cost-benefit of unmanned stores has not yet been compared to the labor costs required to operate the online grocery pickup or delivery options by grocery stores. However, if measured in the future, the profitability of unmanned stores would have a great potential to exceed online groceries. Additionally, unmanned stores create more profitability over online groceries by being able to more accurately collect and analyze consumer data that can then be used to generate more accurate predictions and forecasts about demand the offered service will receive (Magana 2019). Online groceries can collect data of customers through shopping preferences they make online but camera vision and AI sensors in unmanned stores can collect data on which customers linger near what products and what types of impulse buys do a certain customer make. These are the sorts of qualitative data that unmanned stores can collect that could increase their profitability over online groceries. 
Another large cost of online groceries is the last-mile delivery (Magana 2019). Last-mile delivery (LMD) is the final delivery distance required from a transportation hub to the final destination and this accounts for $30 \%$ of total e-logistics cost (Wang et al. 2014). These costs are considered to be quite high because of the huge undertaking it requires to send packages to its end-user. However, this is not an issue that is encountered in unmanned stores because customers would be traveling to the store itself. The customer would be responsible for driving from their home to the store and so the cost of LMD is eradicated.

Unmanned stores are a new evolution of multi-channel retailing that is mostly concentrated in the grocery industry. This study analyzed the sustainability impact of unmanned stores, specifically focusing on the sustainability and economic impact, barriers, and opportunities that exist in these stores' expansion. Most consumers believe that technological advancements in retailing such as automation and robots harm communities while only serving to increase the profits of companies. However, our research concludes that there are several sustainability benefits of these stores ranging from increased efficiency gains to reducing waste through dynamic pricing to increasing a higher educated workforce for the expansion of these stores. For the economic analysis of the grocery stores, it was found that there are many opportunities in the use of data analytics to increase revenue, efficiency, and decrease costs. Using data analytics in the value chain, companies in the unmanned stores' space can gather data of the products they sell throughout their supply chain as well as gather data on customer preferences and satisfaction. A strong digital infrastructure is needed to efficiently use data analytics, and this use of data analytics can be help increase the environmental and social sustainability effects of unmanned stores. If unmanned stores' expansion is approached strategically with different partners who are experts in their respective fields, they can create benefits that go further than just profits for a company. Future work should be done to examine real unmanned retail store data to find what impacts there are to job employment and how the dynamic pricing system affects food waste and sustainability.

Availability of data and material The datasets generated during and/or analyzed during the current study are available from the corresponding author on reasonable request.

\section{Declarations}

Conflict of interest The authors declare that they have no known competing financial interests or personal relationships that could have appeared to influence the work reported in this paper.

\section{References}

AIIB.org. (2020) Digital infrastructure sector analysis. https://www.aiib.org/en/policies-strategies/opera tional-policies/digital-infrastructure-strategy/.content/_download/Full-DISA-Report_final-withAppendix-2020-01-10.pdf. Accessed 10 Aug 2020

Aly M (2020) Factors, barriers, and attitudes affecting the adoption of digital technologies by NZ cooperative retailers. J Asia Entrep Sustain 16(5):169-209

Baumgartner RJ (2011) Critical perspectives of sustainable development research and practice. J Clean Prod 19(8):783-786. https://doi.org/10.1016/j.jclepro.2011.01.005 
Begley S (2019) Automation in retail: an executive overview for getting ready. http://www.mckinsey. com/industries/retail/our-insights/automation-in-retail-an-executive-overview-for-getting-ready. Accessed 10 Aug 2020

Bell D, Gallino S, Moreno A (2015) Showrooms and information provision in omni-channel retail. Prod Oper Manag 24(3):360-362. https://doi.org/10.1111/poms.12258_2

Bessen J (2019) Automation and jobs: when technology boosts employment. Econ Policy 34(100):589626. https://doi.org/10.1093/epolic/eiaa001

Buzby JC et al (2009) Supermarket loss estimates for fresh fruit, vegetables, meat, poultry, and seafood and their use in the ERS loss-adjusted food availability data. U.S. Department of Agriculture, Economic Research Service. EIB-44

Chang W-J et al (2019) A deep learning facial expression recognition based scoring system for restaurants. IEEE. https://doi.org/10.1109/ICAIIC.2019.8668998

Childs M, Blanchflower T, Hur S, Matthews D (2020) Non-traditional marketplaces in the retail apocalypse: investigating consumers' buying behaviours. Int J Retail Distrib Manag 48(3):262-286

Chung J, Li D (2010) A simulation on impacts of a dynamic pricing model for perishable foods on retail operations productivity and customer behaviors. Paper presented at the 2010 IEEE international conference on industrial engineering and engineering management. https://doi.org/10.1109/ieem. 2010.5674391

Dunne JB, Chambers KJ, Giombolini KJ, Schlegel SA (2011) What does "local" mean in the grocery store? multiplicity in food retailers' perspectives on sourcing and marketing local foods. Renew Agric Food Syst 26(1):46-59

Brush M (2019) What Amazon's brick-and-mortar disruption could look like. Supermarket News

Farzan A (2019) When a deep red town's only grocery closed, city hall opened its own store. Just don't call it 'socialism. https://www.washingtonpost.com/nation/2019/11/22/baldwin-florida-food-desertcity-owned-grocery-store/. Accessed 10 Aug 2020

Feagan R, Morris D, Krug K (2004) Niagara region farmers' markets: local food systems and sustainability considerations. Local Environ 9(3):235-254. https://doi.org/10.1080/1354983042000219351

Global Datapoint (2018) JD's unmanned store moves into Indonesia in first overseas expansion

Gunders D (2012) Wasted: how America is losing up to 40 percent of its food from farm to fork to landfill. Natural Resource Defense Council, pp 1-26

Hakovirta M, Denuwara N (2020) How COVID-19 redefines the concept of sustainability. Sustainability 12(9):3727

Hazimihalis K (2018) 3 eye-opening facts about grocery store waste. https://www.dumpsters.com/blog/ grocery-store-food-waste-statistics. Accessed 10 Aug 2020

Heard BR, Bandekar M, Vassar B, Miller SA (2019) Comparison of life cycle environmental impacts from meal kits and grocery store meals. Resour Conserv Recycl 147:189-200

Helm S, Kim SH, Van Riper S (2020) Navigating the 'retail apocalypse': a framework of consumer evaluations of the new retail landscape. J Retail Consum Serv 54:101683

Herbon A, Eugene K (2017) Optimal dynamic pricing and ordering of a perishable product under additive effects of price and time on demand. Eur J Oper Res 260(2):546-556

Hübner A, Wollenburg J, Holzapfel A (2016) Retail logistics in the transition from multi-channel to omni-channel. Int J Phys Distrib Logist Manag 46(6/7):562-583. https://doi.org/10.1108/ IJPDLM-08-2015-0179

Ilijason R (2020) Unmanned grocery stores help improve access to healthy food. https://foodtechconnect. com/2016/05/04/unmanned-grocery-stores-help-improve-access-healthy-food/. Accessed 10 Aug 2020

Internet Retailer Research Online Food Report (2018), pp 1-79

Jedermann R, Nicometo M, Uysal I, Lang W (2014) Reducing food losses by intelligent food logistics. Philos Trans R Soc Lond Ser A Math Phys Eng Sci 372(2017):20130302-20130302

Keen C, Wetzels M, Ruyter KD, Feinberg R (2001) E-tailers versus retailers: which factors determine consumer preferences. METEOR, Maastricht University School of Business and Economics, vol 40

Le T, Liaw S-Y (2017) Effects of pros and cons of applying big data analytics to consumers' responses in an e-commerce context. Sustainability 9(5):798

Madhani PM (2018) Building customer-focused supply chain strategy with 4r model. J Contemp Manag Res 12(1):14-32

Magana G (2019) The online grocery report: the market, drivers, key players, and opportunities in a rising segment of e-commerce. Bus Insider Intell 1:1-36 
MENA Report (2016) United States: IBM introduces dynamic pricing to help retailers navigate online price wars

Meyer S (2018) Is "retail apocalypse" in store? MMR (new York, N.y.) 35(1):41

Murayama H (2019) China's unmanned store boom ends as quickly as it began. http://www.FT.Com. Accessed 10 Aug 2020

Nayak R et al (2015) RFID in textile and clothing manufacturing: technology and challenges. Fash Text 2(1):1-16

Olenik S, Lee HS, Güder F (2021) The future of near-field communication-based wireless sensing. Nat Rev Mater 6:286-288. https://doi.org/10.1038/s41578-021-00299-8

RFID Journal (2021) How much does an RFID tag cost today? https://www.rfidjournal.com/faq/howmuch-does-an-rfid-tag-cost-today. Accessed 10 Aug 2020

Solano A, Duro N, Dormido R, González P (2017) Smart vending machines in the era of internet of things. Future Gener Comput Syst 76:215-220

Statista (2020) Topic: apparel market in the U.S. https://www.statista.com/topics/965/apparel-market-inthe-us/. Accessed 10 Aug 2020

Takada H, Dipak J (1991) Cross-national analysis of diffusion of consumer durable goods in Pacific Rim countries. J Mark 55(2):48-54

The Insight Partners Report (2020) Unmanned convenience store market to 2027, pp 1-114

Traub TL (2017) Mix of markets reveals retail scene in transition. Ark Bus 34(25):4

Treuhaft S, Karpyn A (2010) The grocery gap: who has access to fresh food and why that matters. PolicyLink. http://thefoodtrust.org/uploads/media_items/grocerygap.original.pdf. Accessed 10 Aug 2020

U.S. EPA (2016) Food loss prevention options for grocery stores (1-2)

Wang X, Li D (2012) A dynamic product quality evaluation-based pricing model for perishable food supply chains. Omega (oxford) 40(6):906-917. https://doi.org/10.1016/j.omega.2012.02.001

Wang X, Zhan L, Ruan J, Zhang J (2014) How to choose "last mile" delivery modes for e-fulfillment. Math Probl Eng 2014:1-11

Wasteless wants to help grocery stores waste less food using dynamic pricing (2017). http://www.digit altrends.com. https://www.digitaltrends.com/home/wasteless-dynamic-pricing/

Webb J, Naselli V (2007) Paper route. Print Impr 49(8):42

Wilkie D (2018) Does Amazon's newly open cashier-less grocery store threaten retail jobs? HRnews

Zheng Y, Li Y (2018) Unmanned retail's distribution strategy based on sales forecasting. Paper presented at the 2018 8th international conference on logistics, informatics and service sciences (LISS). https://doi.org/10.1109/LISS.2018.8593273

Zhu L, Wang P, Xi S (2018) Mean-variance analysis of retailers deploying RFID-enabled smart shelves. Information 9(2):40 